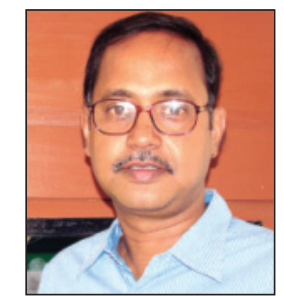

JOURNAL OF MINES, METALS \& FUELS www.jmmf.info Linked in

DISCUSSION-OPINION-EDITORIAL

Jayanta Bhattacharya

Hony. Chief Editor

\title{
Why a coal mining company should start a partnership with a power producing company
}

Global electric vehicle sales grew by $43 \%$ during 2020 , and in some markets such as Norway or the Netherlands sales outnumber petrol and diesel cars. In Europe overall, electric sales during 2020 exceeded half a million units, while in the United States, the new Biden administration is considering incentives to put millions of electric vehicles on the road. Finally, after much lost time, everything indicates that we have reached the tipping point, that 2021 will mark the beginning of mass adoption of electric vehicles. Few other facts of interest are:

1. Technology: the critical threshold that many considered necessary for the adoption of the electric vehicle as a mainstream automotive technology, consisting of improved and cheaper batteries below $\$ 100$ per kilowatt hour, has recently been surpassed. In addition, battery technology continues to improve continuously, meaning we could soon be able to travel hundred miles on a five-minute charge, and having practically no problems with degradation over time.

2. Emissions regulations: the imposition of emissions limits for vehicle manufacturers in the European Union - calculated on the total number of vehicles sold- has led the traditional car companies to begin switching to electric vehicles as the only way to avoid heavy fines. More and more companies are now considering their engine plants as assets that need to be disposed of urgently, disinvesting at an accelerated pace if emissions targets are to be met. In addition, several countries have brought forward the ban on the sale of petrol and diesel vehicles: in the United Kingdom, news that the target date for the phase-out has been brought forward to 2030 has increased interest in electric vehicles by $500 \%$.

3. The environment: the public perception of evidence that the myths fed by the oil companies were false: electric vehicles are cleaner regardless of the origin of the electricity they consume.

4. Cost: although the price of electric vehicles is still somewhat higher than that of traditional vehicles, the world getting ever-closer to parity, and there is growing evidence that in terms of total costs, running an electric vehicle is far

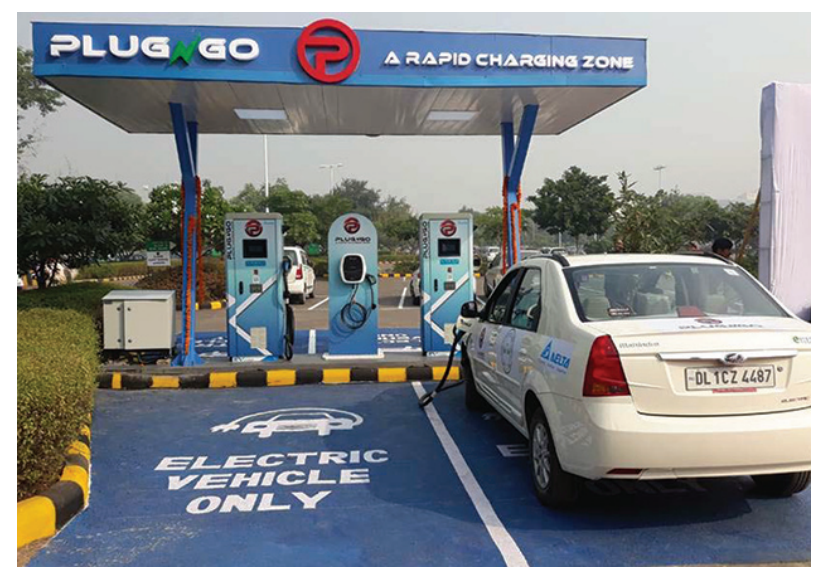

cheaper, partly due to the price differential between electricity and diesel or gasoline, along with low maintenance. This change, in fact, threatens the traditional distribution structure of the automotive industry: one in six Cadillac dealers decided to close rather than follow the brand's recommendations and start selling electric cars. Simply put, when you take maintenance out of the equation, there's not much in it for dealers.

5. A fast-changing market: Volkswagen, copying Tesla, has launched its ID range; GM is pressing ahead with a complete transition; Toyota, after many years on the sidelines of electrification, has finally announced an all-electric vehicle. And then there are companies such as the UK's MG, the alliance between the Chinese technology company Baidu and the automotive giant Geely, the announcement that Hyundai will manufacture electric vehicles designed by Apple, and the major investment round obtained by Rivian. Companies such as Volkswagen, the Renault-NissanMitsubishi consortium or the alliance between Hyundai and Kia match or surpass the all-powerful Tesla in the European market.

At this stage in the game, a coal mining company feeding to a power plant can make partnership to spearhead the business of charging stations and accessories. And there are many more benefits to follow for both of them. 